\title{
Penerapan Lean Manufacturing Untuk Mengidentifikasi Dan Menurunkan Waste (Studi Kasus CV Tanara Textile)
}

\author{
Catur Kusbiantoro dan Ellysa Nursanti \\ Program Studi Teknik Industri, Fakultas Teknologi Industri, Institut Teknologi Nasional Malang \\ E-mail*: koescatur93@gmail.com
}

\begin{abstract}
Abstrak
CV. Tanara Textile merupakan salah satu perusahaan tekstil yang termasuk dalam kelompok industri penyempurnaan kain berupa kain kaos. Pada proses produksi di perusahaan masih ditemukan beberapa waste. Penelitian ini bertujuan untuk mengidentifikasi dan menurunkan waste yang terjadi pada proses produksi maka digunakan pendekatan lean manufacturing. Metode Value Stream Mapping (VSM) digunakan untuk pemetaan aliran produksi dan aliran informasi terhadap suatu produk pada tingkat produksi total, melakukan wawancara untuk pembobotan penyebab 7 waste yang sering terjadi pada proses produksi, VALSAT untuk menganalisa pemborosan dari hasil pembobotan yang selanjutnya melakukan detailed mapping tools, serta analisis FMEA untuk mengetahui penyebab kegagalan proses yang terjadi di lini produksi lalu menghitung nilai RPN tertinggi. Selanjutnya melakukan usulan perbaikan untuk menurunkan waste unnecessary inventory serta menganalisis perbaikan secara berkelanjutan dengan PDCA. Waste terbesar ada pada Unncessary Inventory sebesar 28,571\% faktor penyebabnya adalah penumpukan bahan baku, work in process (WIP), sparepart yang tidak terpakai dan penimbunan pada finished goods Sebelum perbaikan proses produksi 16 hari 9 jam dimana Value Added 6 hari 4 jam dan Lead Time 10 hari 4 jam, setelah perbaikan proses produksi menjadi 14 hari 5 jam dimana Value Added 6 hari 4 jam dan Lead Time 8 hari 1 jam, dengan demikian dapat meningkatkan process cycle efficiency sebesar 17,19\% dan menghemat lead time sebesar 2,546\% dengan penurunan waste sebesar $8,31 \%$.
\end{abstract}

Kata Kunci : FMEA, Lean Manufacturing, PDCA, VALSAT, VSM, Waste

\section{Pendahuluan}

Usaha yang nyata dalam suatu produksi barang adalah mengurangi pemborosan yang tidak mempunyai nilai tambah dalam berbagai hal termasuk penyediaan bahan baku, lalu lintas bahan, pegerakan operator, pegerakan alat dan mesin, menunggu proses, kerja ulang dan perbaikan [1]. Ide utamanya adalah pencapaian secara menyeluruh efisiensi produksi dengan mengurangi pemborosan (waste)[2]. CV Tanara Textile merupakan salah satu perusahaan tekstil yang termasuk dalam kelompok industri penyempurnaan kain berupa kain kaos. Dari hasil pengamatan awal diketahui bahwa di dalam aliran proses produksinya perusahaan masih sering mengalami hambatan-hambatan ataupun aktivitasaktivitas yang tidak memberikan nilai tambah sehingga dapat mengurangi profit bagi perusahaan.

Tabel 1 Data Waste Produksi

\begin{tabular}{|l|r|}
\hline \multicolumn{1}{|c|}{ Waste } & $\begin{array}{c}\text { Condition } \\
(\mathrm{m} / \text { bulan) }\end{array}$ \\
\hline Over Production & 152,39 \\
\hline Defect & 92,67 \\
\hline Unnecessary Inventory & 325 \\
\hline $\begin{array}{l}\text { Inappropriate } \\
\text { processing }\end{array}$ & 125 \\
\hline
\end{tabular}




\begin{tabular}{|l|r|}
\hline Excessive Tranportations & 106 \\
\hline Waiting/Idle & 280 \\
\hline Unnescessary Motion & 95 \\
\hline
\end{tabular}
Sumber : Data perusahaan tahun 2015

Pada tabel 1 dapat dijelaskan bahwa kolom waste Unncessary Inventory merupakan jenis waste yang paling dominan tidak berguna dan tidak memberi nilai tambah pada produksi. Permasalahan yang terjadi di CV. Tanara Textile pada akhirnya akan berdampak pada pemborosan waktu produksi akibat terdapatnya aktivitas yang tidak efisien atau tidak mempunyai nilai tambah (non value added) [3]. Oleh sebab itu penting untuk melakukan penelitian dengan penerapan sistem Lean Manufacturing dengan tujuan penelitian yang dilakukan di CV. Tanara Textile adalah untuk mengidentifikasi penyebab waste dan menurunkan waste pada proses produksi.

\section{Metode Penelitian}

Adapun tahapan metode penelitian tersebut sebagai berikut:[4]

\section{- Pengumpulan Data}

Melakukan survei pendahuluan, yaitu survei langsung ke perusahaan yang dituju untuk memperoleh gambaran dan mencari tahu permasalahan yang terjadi pada perusahaan. Merumuskan masalah penelitian sesuai dengan masalah yang hasil survei pendahuluan yang telah dilaksanakan. Survei lapangan dilakukan untuk memperoleh data-data yang digunakan, seperti permintaan kebutuhan pelanggan, proses aliran informasi, proses aliran fisik, aktivitas produksi, aktivitas pemesanan, serta informasi kebutuhan tiap tenaga kerja. Sedangkan, studi kepustakaan dilakukan untuk mendukung studi lapangan dengan cara mencari jurnal-jurnal dan buku-buku serta artikel terkait yang berhubungan dengan masalah yang diteliti.

\section{- Pengolahan Data}

Menggambarkan Value Stream Mapping (VSM) untuk mengetahui aliran informasi dan aliran fisik pada sistem produksi kain di CV. Tanara Textile. Mengidentifikasi penyebab terjadinya waste yang paling dominan pada lini produksi. Meneliti value dan not value stream dan mengolah data menggunakan VSM. Mengidentifikasi dan menganalisis waste yang timbul menggunakan FMEA. Mengidentifikasi timbulnya waste dengan VALSAT di lantai produksi dan mengidentifikasi faktorfaktor timbulnya waste tools yang digunakan. Merancang usulan perbaikan dengan menggunakan PDCA untuk mengeliminasi waste yang terjadi di lantai produksi berdasarkan analisa yang telah dilakukan.. Selanjutnya embuatan kesimpulan dan saran atas hasil penelitian yang dilakukan.

\section{Hasil}

\section{Value Stream Mapping (VSM)}

Metode Value Stream Mapping (VSM) untuk pemetaan aliran produksi dan aliran informasi terhadap suatu produk pada tingkat produksi total, mengidentifiksaikan dimana terjadinya waste, serta menggambarkan value added dan lead time yang dibutuhkan berdasarkan dari masing-masing karakteristik proses yang terjadi.[5] 


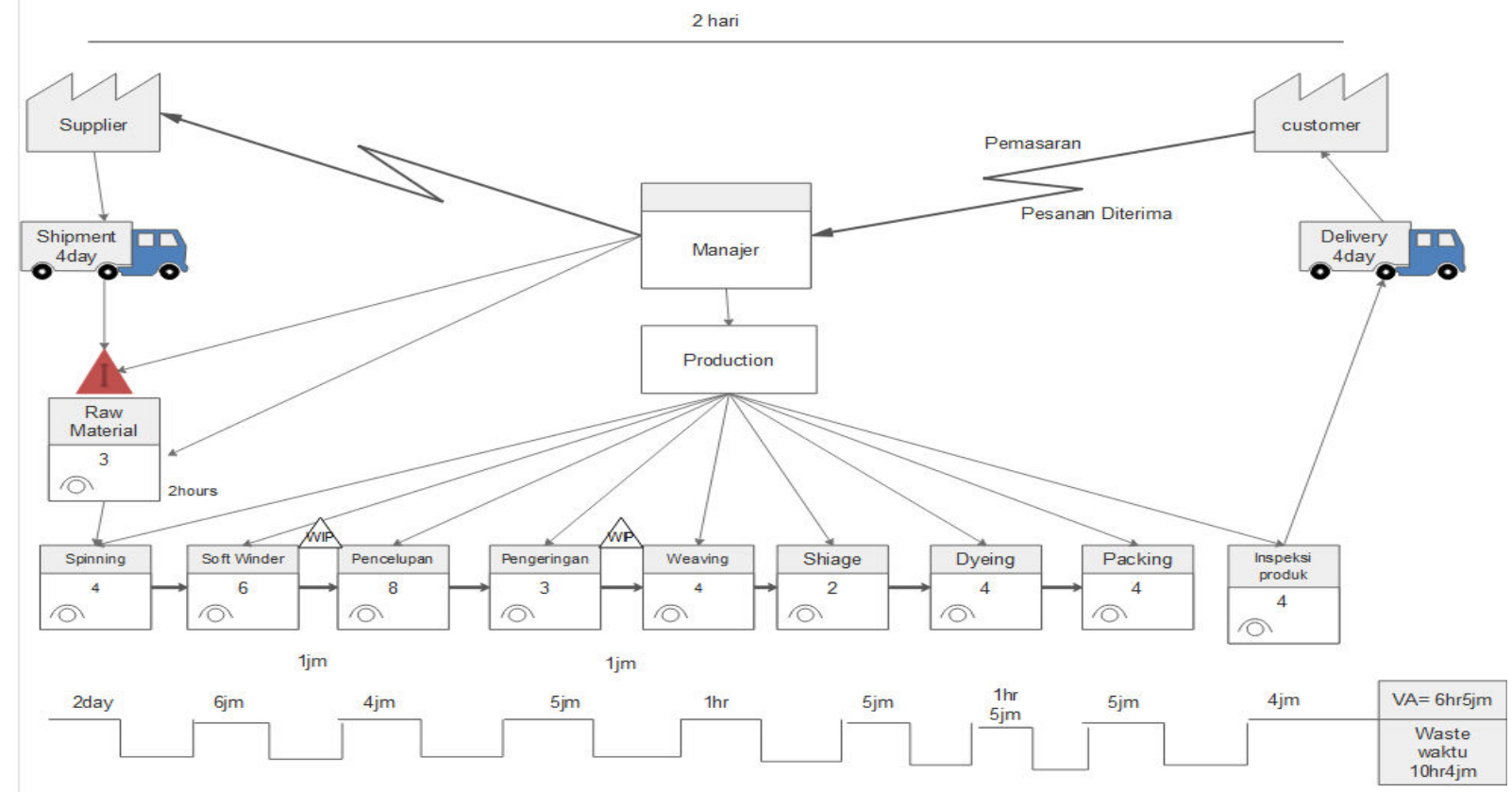

Gambar 1 Value Stream Mapping

Value added sebesar 6 hari 3 jam Lead Time merupakan waktu yang diperlukan bagian produksi untuk memproduksi item produk per capacity yang sudah ditentukan. Waste waktu dari proses produksi adalah sebesar 10 hari 4 jam, ada lead time dan idle time. Lead time waktu tunggu material sebelum datang ke gudang bahan baku dan pengiriman produk ke konsumen dengan proporsi waktu yang diperlukan sebesar 8 hari. Idle time waktu tunggu konfrimasi pemesanan oleh manajer, proses-proses produksi seperti adanya WIP (work in process) dan Inspeksi terhadap material dengan proporsi waktu yang diperlukan sebesar 2 hari 4 jam. Perhitungan Process Cycle Efficiency Value added 6 hari 5 jam = 544320 detik Lead Time 10 hari 4 jam $=898560$ detik

Process Cycle Efficiency $=\frac{\text { value added }}{\text { Lead Time }} \times 100 \%$

$$
\begin{aligned}
& =\frac{544320}{898560} \times 100 \% \\
& =60,58 \%
\end{aligned}
$$

\section{Identifikasi Seven Waste}

Untuk melakukan pembobotan identifikasi maka peneliti melakukan wawancara langsung dengan manager pabrik dan karyawan yang kerja di masing-masing proses produksi berjumlah 5-10 orang.

Tabel 2 Hasil Wawancara Waste

\begin{tabular}{llcc}
\hline No & Pemborosan & Poin & Bobot $(\%)$ \\
\hline & & & \\
1 & Overproduction & 2 & 14,386 \\
2 & Defect & 1 & 7,143 \\
3 & Unncessary Inventory & 4 & 28,571 \\
4 & Inappropriate Processing & 2 & 14,286 \\
5 & Excessive Transporstation & 1 & 7,143 \\
6 & Waiting & 3 & 21,429 \\
7 & Unncessary Motion & 1 & 7,143 \\
\hline Total & & 15 & 100 \\
\hline
\end{tabular}

Berikut ini merupakan analisa waste yang terjadi berdasarkan poin tertinggi sampai terendah dari hasil wawancara 7 pemborosan.

1. Unnecessary inventory $=$ terdapat penumpukan inventory dalam waktu lama (extra storage) karena material yang datang segera diproses untuk difabrikasi mengingat material datang lebih lambat dari jadwal. Inventory in process terjadi karena barang yang sudah diproses harus menunggu komponen 
lainnya datang untuk kemudian difabrikasi bersama. Kebutuhan sparepart yang sebagian tidak terpakai untuk kebutuhan mesin (cost) dan membutuhkan space storage.

2. Waiting = menyebabkan poor workflow dan poor material flow sehingga berpotensi timbulnya keterlambatan pengiriman. Waste ini terjadi karena lamanya material sampai di lantai produksi sebagai akibat lamanya proses pencarian pemasok dan lamanya material tertahan di pelabuhan

3. Overproduction $=$ overproduction memakan tempat yang sudah mulai mengganggu flow process

4. Inappropriate processing $=$ terdapat pengerjaan yang dilakukan tidak sesuai spesifikasi sehingga menimbukan efek pada hasil processing.

5. Defect $=$ defect yang terjadi membutuhkan proses rework atau berpotensi menimbulkan reschedule

6. Excessive Transportation = terjadi transportasi berlebih namun belum mengganggu proses produksi. Permasalahan waste jenis ini tidak dapat diulas lebih mendalam karena layout lantai produksi tidak seperti layout untuk pabrik dengan tipe pengerjaan seri yang waktu dan jarak tiap work station sangat berpengaruh terhadap perubahan kecil

7. Unnecessary motion = terdapat pergerakan yang tidak perlu namun belum mengganggu proses produksi. Dalam melakukan aktifitas pengerjaanya selama ini operator dapat dikatakan sudah berada dalam lingkungan kerja yang cukup nyaman.

\section{Value Stream Analysis Tools (VALSAT)}

Pemilihan ini didasarkan bahwa value stream mapping dengan nilai terbesar tersebut paling sesuai untuk mengidentifikasi waste pada value stream[6].

Tabel 3 dapat dijelaskan bahwa $\mathrm{H}$ (High correlation) faktor pengali 9. M (Medium correlation) faktor pengali 3, L (Low correlation) faktor pengali 1. Dapat diketahui bahwa tools yang terpilih dengan skor terbesar adalah Process Activity Mapping dengan total 87. Proses selanjutnya akan dibuat detailed mapping dari Process Acitvity Mapping (PAM) tersebut.

Tabel 3 Hasil Rekapitulasi

\begin{tabular}{|c|c|c|c|c|c|c|c|}
\hline Waste & $\begin{array}{l}\text { Process } \\
\text { Activity } \\
\text { Mappin } \\
\text { g }\end{array}$ & $\begin{array}{l}\text { Supplay } \\
\text { Chain } \\
\text { Respons e } \\
\text { Matrik }\end{array}$ & $\begin{array}{l}\text { Product } \\
\text { ion } \\
\text { Variety } \\
\text { Funnel }\end{array}$ & $\begin{array}{l}\text { Quality } \\
\text { Filter } \\
\text { Mappin } \\
\text { g }\end{array}$ & $\begin{array}{l}\text { Demand } \\
\text { Amplificati } \\
\text { on } \\
\text { Mapping }\end{array}$ & $\begin{array}{l}\text { Decisio } \\
\text { n Point } \\
\text { Analysi } \\
\text { s }\end{array}$ & $\begin{array}{l}\text { Pysical } \\
\text { Struvtu } \\
\text { re }\end{array}$ \\
\hline Overproduction & L 2 & M 6 & 0 & L 2 & M 6 & M 6 & 0 \\
\hline Waiting & H 27 & H 27 & L 3 & 0 & M 6 & M 6 & 0 \\
\hline Transportation & H 9 & 0 & 0 & 0 & 0 & 0 & L 1 \\
\hline Unappropriate Processing & H 18 & 0 & M 6 & L 2 & 0 & $\mathrm{~L} 2$ & 0 \\
\hline Unnecessary Inventory & M 12 & H 36 & M 12 & 0 & H 36 & M 12 & $\mathrm{~L} 4$ \\
\hline Unnecessary Motion & H 18 & L 1 & 0 & H 18 & 0 & 0 & 0 \\
\hline Defect & L 1 & 0 & 0 & 0 & 0 & 0 & 0 \\
\hline Total & 87 & 70 & 21 & 22 & 48 & 22 & 5 \\
\hline
\end{tabular}

Tabel 4 menjelaskan tentang pengelompokan aktivitas berdasarkan nilai tambah (VA), aktivitas tidak bernilai tambah tapi masih dibutuhkan (NNVA), dan tidak memiliki nilai tambah sama sekali

Tabel 4 Process activity mapping

\begin{tabular}{|c|c|c|c|c|c|c|c|c|c|c|}
\hline \multirow[t]{2}{*}{ No } & \multirow[t]{2}{*}{ Flow process } & \multirow[t]{2}{*}{ Jarak } & \multirow[t]{2}{*}{ Waktu } & \multirow{2}{*}{$\begin{array}{l}\text { Oper } \\
\text { ator }\end{array}$} & \multicolumn{5}{|c|}{ Aktivitas } & \multirow{2}{*}{$\begin{array}{l}\text { VA/NV } \\
\text { A/NNV } \\
\text { A }\end{array}$} \\
\hline & & & & & $\mathrm{O}$ & $\mathrm{T}$ & I & S & $\mathrm{D}$ & \\
\hline 1 & $\begin{array}{l}\text { Menunggu } \\
\text { konfrimasi dari } \\
\text { manajer }\end{array}$ & & 2 hari & & $\mathrm{O}$ & $\mathrm{T}$ & I & $\mathrm{S}$ & $\mathrm{D}$ & NNVA \\
\hline 2 & $\begin{array}{l}\text { Jangka Waktu } \\
\text { Pengiriman }\end{array}$ & & 4 hari & & $\mathrm{O}$ & $\mathrm{T}$ & I & $\mathrm{S}$ & $\mathrm{D}$ & NNVA \\
\hline 3 & Mengelola gudang & & 4 hari & & $\mathrm{O}$ & $\mathrm{T}$ & I & $S$ & $\mathrm{D}$ & NVA \\
\hline 4 & $\begin{array}{l}\text { Inspeksi Raw } \\
\text { Material }\end{array}$ & 15 & 2 jam & 3 & $\mathrm{O}$ & $\mathrm{T}$ & I & $S$ & $\mathrm{D}$ & VA \\
\hline 5 & Proses Spinning & 7 & 4 hari & 4 & $\mathrm{O}$ & $\mathrm{T}$ & $\mathrm{I}$ & $\mathrm{S}$ & $\mathrm{D}$ & $\begin{array}{l}\mathrm{V} \\
\mathrm{A}\end{array}$ \\
\hline
\end{tabular}


Jurnal Teknologi dan Manajemen Industri, Vol. 5 No. 1, Februari 2019

Pascasarjana Institut Teknologi Nasional Malang

\begin{tabular}{|c|c|c|c|c|c|c|c|c|c|c|}
\hline 6 & Set up Inspeksi & & 20 menit & & $\mathrm{O}$ & $\mathrm{T}$ & I & $\mathrm{S}$ & $\mathrm{D}$ & NNVA \\
\hline 7 & Soft Winder & 7 & $6 \mathrm{jam}$ & 6 & $\mathrm{O}$ & $\mathrm{T}$ & I & $\mathrm{S}$ & $\mathrm{D}$ & VA \\
\hline 8 & Set up inpeksi & & 20 menit & & $\mathrm{O}$ & $\mathrm{T}$ & I & $\mathrm{S}$ & $\mathrm{D}$ & NNVA \\
\hline 9 & WIP & 3 & 2 jam & & $\mathrm{O}$ & $\mathrm{T}$ & I & $\mathrm{S}$ & $\mathrm{D}$ & NVA \\
\hline 10 & Pencelupan & 4 & 2 jam & 8 & $\mathrm{O}$ & $\mathrm{T}$ & I & $\mathrm{S}$ & $\mathrm{D}$ & VA \\
\hline 11 & Inspeksi & & 20 menit & & $\mathrm{O}$ & $\mathrm{T}$ & I & $\mathrm{S}$ & $\mathrm{D}$ & NNVA \\
\hline 12 & Pengeringan & 4 & 5 jam & 3 & $\mathrm{O}$ & $\mathrm{T}$ & I & $\mathrm{S}$ & $\mathrm{D}$ & $\mathrm{VA}$ \\
\hline 13 & Inspeksi & & 20menit & & $\mathrm{O}$ & $\mathrm{T}$ & I & $\mathrm{S}$ & $\mathrm{D}$ & NNVA \\
\hline 14 & WIP & 3 & 2 jam & & $\mathrm{O}$ & $\mathrm{T}$ & I & $\mathrm{S}$ & $\mathrm{D}$ & NVA \\
\hline 15 & Weaving & 7 & 1 hari & 4 & $\mathrm{O}$ & $\mathrm{T}$ & I & $\mathrm{S}$ & $\mathrm{D}$ & VA \\
\hline 16 & Set up Inspeksi & & 20 menit & & $\mathrm{O}$ & $\mathrm{T}$ & I & $\mathrm{S}$ & $\mathrm{D}$ & NNVA \\
\hline 17 & Shiage & 5 & 5 jam & 2 & $\mathrm{O}$ & $\mathrm{T}$ & I & $\mathrm{S}$ & $\mathrm{D}$ & VA \\
\hline 18 & Dyeing & & 1 hari 5 jam & 4 & $\mathrm{O}$ & $\mathrm{T}$ & I & $\mathrm{S}$ & $\mathrm{D}$ & VA \\
\hline 19 & Set up Inspeksi & & 20 menit & & $\mathrm{O}$ & $\mathrm{T}$ & I & $\mathrm{S}$ & $\mathrm{D}$ & NNVA \\
\hline 20 & Packing & 5 & 5 jam & 4 & $\mathrm{O}$ & $\mathrm{T}$ & I & $\mathrm{S}$ & $\mathrm{D}$ & VA \\
\hline 21 & Cek Produk Jadi & 3 & 4 jam & 4 & $\mathrm{O}$ & $\mathrm{T}$ & I & $\mathrm{S}$ & $\mathrm{D}$ & VA \\
\hline 22 & $\begin{array}{l}\text { Delivery ke } \\
\text { Costumer }\end{array}$ & & 4hari & 2 & $\mathrm{O}$ & $\mathrm{T}$ & I & $\mathrm{S}$ & $\mathrm{D}$ & VA \\
\hline & Total & & 16 hari $9 \mathrm{jam}$ & & $\begin{array}{l}1 \\
1\end{array}$ & 1 & 7 & 3 & 2 & \\
\hline
\end{tabular}

Pada tabel 5 menjelaskan tentang total waktu proses produksi kain adalah selama 1.540.080 detik, total aktivitas 24, 1loperasi, 1 transportasi, 7 inspeksi, 3 storage dan 2 delay yang terdapat dalam aktivitas. Bahwa ada 11 yang tergolong pada aktivitas yang bernilai tambah (VA) dengan prosentase 35,327\% dari keseluruhan aktivitas, yang tidak bernilai tambah (NVA) ada 3 prosentase sebesar 29,90\% aktivitas ini merupakan aktivitas yang paling banyak membutuhkan lead time produksi, dan aktivitas yang tidak memberi nilai tambah tapi masih dibutuhkan (NNVA) ada 7 nilai prosentase sebesar 34,782\% terhadap total lead time produksi.

Tabel 5 Prosentase VA NVA NNVA

\begin{tabular}{|l|l|r|}
\hline Jenis & Jumlah & $\begin{array}{c}\text { Waktu } \\
\text { (detik) }\end{array}$ \\
\hline Operation ( O ) & 11 & 544.320 \\
Transportation ( T ) & 1 & 345.600 \\
Inspection ( I ) & 7 & 10.800 \\
Storage ( S ) & 3 & 120.960 \\
Delay ( D ) & 2 & 518.400 \\
\hline Total & $\mathbf{2 4}$ & $\mathbf{1 . 5 4 0 . 0 8}$ \\
VA & 11 & $\mathbf{0}$ \\
NVA & 3 & 344.320 \\
NNVA & 7 & 535.520 \\
& \multicolumn{3}{|c|}{$\mathbf{1 . 5 4 0 . 0 8 0}$} \\
Total Waktu & 35,327 \\
\%VA & 29,90 \\
\%NVA & \multicolumn{2}{|c|}{34,782} \\
\%NNVA & \multicolumn{2}{|c|}{} \\
\cline { 2 - 3 } & \multicolumn{2}{|c|}{} \\
\cline { 2 - 3 }
\end{tabular}

\section{FMEA}

Prosedur terstruktur untuk mengidentifikasi dan mencegah sebanyak mungkin mode kegagalan (failure mode)[7], bahwa nilai RPN tertinggi adalah 324 dengan penumpukan bahan baku dan 200 dengan penimbunan barang dapat dilihat pada tabel 6 . 
Jurnal Teknologi dan Manajemen Industri, Vol. 5 No. 1, Februari 2019

Pascasarjana Institut Teknologi Nasional Malang

Tabel 6 FMEA

\begin{tabular}{|c|c|c|c|c|c|c|c|}
\hline $\begin{array}{l}\text { Process } \\
\text { Step }\end{array}$ & $\begin{array}{l}\text { Potential } \\
\text { Failure Effect }\end{array}$ & $\begin{array}{l}\text { Sever } \\
\text { ity }(S)\end{array}$ & Potential Causes & $\begin{array}{l}\text { Occuran } \\
\text { ce }(O)\end{array}$ & Current Controls & $\begin{array}{l}\text { Detecti } \\
\text { on }(D)\end{array}$ & $\begin{array}{l}R P N \\
\text { SxOxD }\end{array}$ \\
\hline \multirow{4}{*}{ 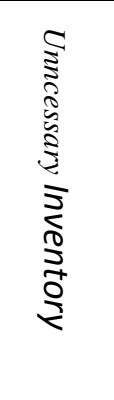 } & $\begin{array}{l}\text { Penumpukan } \\
\text { Bahan Baku }\end{array}$ & 9 & $\begin{array}{l}\text { Kurangnya } \\
\text { Penjadwalan Bahan } \\
\text { Baku Yang Tepat }\end{array}$ & 6 & $\begin{array}{l}\text { Additional Space } \\
\text { Storage }\end{array}$ & 6 & 324 \\
\hline & $\begin{array}{l}\text { Penimbunan } \\
\text { Barang Jadi }\end{array}$ & 8 & $\begin{array}{l}\text { Adanya produksi } \\
\text { yang berlebih }\end{array}$ & 5 & $\begin{array}{ll}\text { Ditempatkan } & \\
\text { diruangan } & \text { yang } \\
\text { kosong } & \end{array}$ & 5 & 200 \\
\hline & Work In Process & 3 & $\begin{array}{l}\text { Kurangnya setup } \\
\text { mesin }\end{array}$ & 4 & $\begin{array}{l}\text { Mengurangi waktu } \\
\text { yang dilakukan }\end{array}$ & 4 & 60 \\
\hline & $\begin{array}{l}\text { Sparepart tidak } \\
\text { terpakai }\end{array}$ & 4 & $\begin{array}{l}\text { Belum ada jadwal } \\
\text { untuk pergantian } \\
\text { sparepart }\end{array}$ & 4 & $\begin{array}{l}\text { Control terhadap } \\
\text { sparepart yng akan } \\
\text { digunakan }\end{array}$ & 4 & 80 \\
\hline
\end{tabular}

\section{Usulan Perbaikan \\ Value Stream Mapping}

Setelah melakukan perbaikan future state mapping hasil yang diperoleh pada value added adalah sebesar 6 hari 3 jam value added disini nilainya tetap karena tidak berpengaruh pada proses produksi. lead time yang harus diturunkan valuenya karena mengganggu dari flow process produksi dari sebelumnya sebesar 10,5 hari menjadi 8,1 hari dan Process Cycle efficiency yang semula 60,58\% naik menjadi $77,77 \%$ berarti proses produksi meningkat secara efisien dan efektif.

\section{Process activity Mapping}

Pada process activity mapping future state memberikan gambaran aliran fisik dan informasi, waktu yang diperlukan untuk setiap aktivitas, setelah perbaikan dengan menurunkan waktu produksi pada proses WIP, melakukan penjadwalan bahan baku secara (MRP). Tabel 7 merupakan perbandingan awal sebelum dan sesudah perbaikan maka diketahui nilai waktu siklusnya turun sebesar 259.200 detik.

Tabel 7 Tabel Sebelum dan Sesudah Perbaikan

\begin{tabular}{|l|c|c|}
\hline Indikator & Kondisi Awal & $\begin{array}{l}\text { Setelah } \\
\text { Perbaikan }\end{array}$ \\
\hline PCE & $60,58 \%$ & $77,77 \%$ \\
\hline VA & $35,327 \%$ & $42,495 \%$ \\
\hline NVA & $29,90 \%$ & $24,259 \%$ \\
\hline NNVA & $34,782 \%$ & $32,236 \%$ \\
\hline Waktu Siklus & $\begin{array}{c}\mathbf{1 . 5 4 0 . 0 8 0} \\
\text { detik }\end{array}$ & $\begin{array}{c}\mathbf{1 . 2 8 0 . 8 8 0} \\
\text { detik }\end{array}$ \\
\hline
\end{tabular}

\section{Usulan Unncessary Inventory}

Waste unnecessary inventory merupakan waste yang paling dominan di dalam produksi kain, setelah diketahui penyebab terjadinya waste tersebut maka dibuatlah usulan untuk menurunkan waste unnecessary inventory antara lain[8]: Pengendalian Persediaan dengan metode MRP (Material Requirement Planning), Manajemen Tata Kelola Gudang dan membuat SOP tentang penerimaan bahan baku (raw material)

\section{PDCA}

Identifikasi masalah yang akan dipecahkan dan sebagai patokan perbaikan selanjutnya, perusahaan harus menetapkan standar prosedur perusahaan[9]. Plan menurunkan waste Unncessary Inventory yang terjadi pada proses produksi kain. Do melakukan perencanaan proses yang telah ditetapkan mulai dari penggambaran alur proses produksi, mengidentifikasi penyebab waste dan melakukan penggolongan aktivitas produksi. Check melakukan evaluasi terhadap sasaran dan proses serta melaporkan apa saja hasilnya. Kita mengecek kembali apa yang sudah kita kerjakan, sudahkah sesuai dengan standar yang ada atau masih ada kekurangan. Act melakukan standarisasi pengecekan ulang secara berkelanjutan mempertimbangkan area mana saja yang mungkin diterapkan, melakukan modifikasi standar prosedur dan kebijakan yang ada, melakukan pengendalian persediaan dengan metode MRP (Material Requirement Planning), melakukan manajemen tata kelola gudang dan merancang SOP penerimaan bahan baku (raw material). 


\section{Kesimpulan}

Waste terbesar ada pada Unncessary Inventory sebesar $28,571 \%$ faktor penyebabnya adalah penumpukan bahan baku, work in process (WIP), sparepart yang tidak terpakai dan penimbunan pada finished goods Sebelum perbaikan proses produksi 16 hari 9 jam dimana Value Added 6 hari 4 jam dan Lead Time 10 hari 4 jam, setelah perbaikan proses produksi menjadi 14 hari 5 jam dimana Value Added 6 hari 4 jam dan Lead Time 8 hari 1 jam, demikian dapat meningkatkan process cycle efficiency sebesar $17,19 \%$ dan menghemat lead time sebesar 2,546\% dengan penurunan waste sebesar 8,31\%. Usulan perbaikan untuk menurunkan waste Unncessary Inventory yaitu dengan melakukan penerapan pengendalian persediaan dengan metode MRP (Material Requirement Planning), manajemen tata kelola gudang dan merancang SOP penerimaan bahan baku (Raw Material)

\section{Daftar Referensi}

[1] Nasution M. N., Manajemen Mutu Terjamin (Total Quality Manajemen), Bogor 2005

[2] Gaspersz, Vincent, Lean Six Sigma for manufacturing and Service Industries, PT Gramedia Pustaka, Jakarta, 2007

[3] Hines, P and Taylor, D. Going Lean, Lean Enterprise Research Centre,United Kingdom, 2000

[4] Hazmi F. Widyan, Penerapan Lean Manufacturing untuk Mereduksi Waste, ITS Surabaya Vol. 1 No. ISSN 2301-9271, pp 423-427, 2012

[5] Liker, Jeffrey K., The Toyota Way 14 Prinsip Manajemen Perusahaan Manufaktur Terhebat di Dunia, Erlangga, Jakarta, 2006

[6] Majalah Shitf Indonesia, , Jakarta 2014

[7] Chrysler, C. Potential Failure and Effects Analysis (FMEA), Ford Motor Company, 1995

[8] Danang, S, Meminimasi Waste untuk Perbaikan Produksi Kantong Kemasan Pendekatan Lean manufacturing, Universitas Brawijaya, Malang Vol.1 No.1 ISSN 2338-3925,pp 256-301 2013

[9] Sokovic, M. D Pavletic, Quality Improvement PDCA Cycle, Journal Of Mechanical Engineering, Slovenia 53/6 369-378, pp 256-345 2007 